Expression of Concern

\title{
Expression of Concern on "A Novel Model of Cancer-Induced Peripheral Neuropathy and the Role of TRPA1 in Pain Transduction"
}

\author{
Pain Research and Management
}

Received 11 November 2018; Accepted 11 November 2018; Published 10 December 2018

Copyright (c) 2018 Pain Research and Management. This is an open access article distributed under the Creative Commons Attribution License, which permits unrestricted use, distribution, and reproduction in any medium, provided the original work is properly cited.

Pain Research and Management would like to express concern with the article titled "A Novel Model of CancerInduced Peripheral Neuropathy and the Role of TRPA1 in Pain Transduction" published in Pain Research and Management in December 2017 [1], due to the information that the Faculty Board of the Charité-Universitaetsmedizin Berlin, under the advisement of the responsible ombudsperson, has investigated complaints about this article and has decided to initiate a full investigation. This notice may be updated or replaced based on the outcome of the investigation.

Update, December 2020: The research reported in this article has been subject to legal proceedings at the Verwaltungsgericht Berlin (Berlin Administrative Court). The author did not provide the underlying data to the journal.

\section{References}

[1] A. Maqboul and B. Elsadek, "A novel model of cancer-induced peripheral neuropathy and the role of TRPA1 in pain transduction," Pain Research and Management, vol. 2017, Article ID 3517207, 12 pages, 2017. 